\title{
PENGEMBANGAN FUNGSIONALITAS SISTEM INFORMASI DENGAN PENDEKATAN KANSEI ENGINEERING
}

\author{
Muhamad Nurdin Abdul Muhaemin \\ Program Studi Teknik Informatika, Fakultas Teknik, Universitas Sangga Buana \\ muhamad.nurdin@usbypkp.ac.id
}

\begin{abstract}
Kansei Engineering pada mulanya berorientasi pada dukungan untuk menterjemahkan perasaan pengguna menjadi parameter suatu produk dan menghasilkan pedoman desain untuk produk tersebut agar sesuai dengan harapan sekelompok pengguna. Berbagai literatur yang ada sudah membuktikan bahwa metode kansei engineering bisa dimanfaatkan sebagai pedoman desain untuk antarmuka perangkat lunak bahkan untuk menginvestigasi kebutuhan persyaratan perangkat lunak. Karya tulis ini membahas pengembangan sistem informasi dengan pendekatan Kansei Engineering yang bertujuan supaya fungsionalitas sistem informasi sesuai dengan kebutuhan sekelompok pengguna.
\end{abstract}

Kata Kunci: Sistem Informasi; Kansei Engineering; Pengembangan Perangkat Lunak

\section{PENDAHULUAN}

Ketika seseorang berinteraksi dengan komputer, ia akan melakukan menggunakan cara -cara tertentu baik pada saat memberikan masukan atau menginginkan suatu keluaran. Komputer dan manusia berinteraksi melalui antarmuka perangkat lunak, baik yang berbasis desktop, mobile, web, dan sebagainya[1]. Interaksi tersebut terjadi karena komputer melalui perangkat lunak yang tersedia memberikan fungsi yang dibutuhkan oleh pengguna.

Kebutuhan akan pengembangan sistem informasi untuk mendukung kinerja suatu lembaga menjadi salah satu hal yang sangat diprioritaskan. Berbagai lembaga berlomba untuk mengembangkan sistem informasi untuk mempermudah operasional, sehingga bisa memberikan pelayanan yang terbaik terhadap anggota dari lembaga tersebut termasuk pihak lain yang berkepentingan dengan lembaga tersebut. Pengembangan sistem yang memakan biaya yang relatif mahal menjadi tantangan tersendiri bagi suatu lembaga, termasuk besarnya resiko yang harus diambil jika ternyata pengembangan sistem informasi tersebut mengalami kegagalan. Bukan karena tidak mengikuti alur dari siklus pengembangan perangkat lunak melainkan kurangnya pedoman rancangan yang benar-benar sesuai dengan kebutuhan pengguna.

Pada tahun 1995 seorang peneliti bernama Mitsuo Nagamachi dari Hiroshima University Japan menemukan konsep pengembangan produk yang berorientasi pada rasa pengguna. Kansei Engineering pada mulanya berorientasi pada dukungan untuk menterjemahkan perasaan pengguna menjadi parameter suatu produk dan menghasilkan pedoman desain untuk produk tersebut agar sesuai dengan harapan sekelompok pengguna. Seiring berkembangnya penelitian dalam penerapan kansei engineering, berbagai literatur yang ada sudah membuktikan bahwa metode kansei engineering selain dimanfaatkan sebagai pedoman desain untuk antarmuka perangkat lunak namun bisa juga dimanfaatkan untuk menginvestigasi kebutuhan persyaratan perangkat lunak.

Sistem informasi merupakan program perangkat lunak yang dibangun sesuai dengan kebutuhan suatu organisasi untuk mendukung fungsi operasi organisasi dengan tujuan dapat mempermudah pengaksesan informasi yang dibutuhkan oleh organisasi tersebut maupun pihak lain yang berkepentingan. Adapun fungsionalitas sistem informasi adalah berbagai hal yang bisa dilakukan oleh sistem informasi.

\section{TEORI PENDUKUNG}

\section{Kansei Engineering}

Kansei merupakan kesan subjektif terhadap sesuatu yang ditangkap melalui panca indera[2]. Kansei melibatkan kepekaan, ketepatan, perasaan dan emosi yang di harmoniskan melalui lima indera; penglihatan (vision), pendengaran (hearing), penciuman 
(smell), perasaan (taste), perabaan (skin sensation). Istilah kansei kemudian di terjemahkan dalam sebuah metode perekayasaan bernama Kansei Engineering. Metode ini pertama kali di perkenalkan oleh Mitsuo Nagamachi (Dean of Hirosima Internasional University) sebagai sebuah metode perekayasaan yang baru dalam desain dan pengembangan produk industri yang berorientasi pada perasaan manusia.

Kansei Engineering, yang didasarkan pada disiplin matematika, statistik, psikologi dan rekayasa, diciptakan oleh Profesor Mitsuo Nagamachi dari Hirosima University di tahun 1970-an, untuk memungkinkan pengukuran aspek emosional konsumen terhadap suatu produk, dan menghubungkan hasilnya untuk elemen desain produk [3]. Kansei Engineering sudah digunakan untuk menjadi pedoman desain berbagai produk, Kansei Engineering adalah metode yang memungkinkan pengintegrasian emosi manusia dalam pedoman desain suatu produk. Kansei bersifat unik untuk berbagai objek yang berbeda dan juga unik untuk setiap kelompok pengguna. Kansei engineering menggunakan instrumen pengukuran verbal dalam implementasi metodologinya [4].

Kansei Engineering menyimpulkan kansei pengguna secara subyektif, menganalisa dan memetakan kansei apa yang terkait dengan suatu elemen, sehingga desain produk baru yang dihasilkan berdasarkan pada pedoman desain mencangkup kesan subjektif sekelompok pengguna. Tujuan yang diharapkan adalah produk baru yang dihasilkan bisa menjadikan pengguna merasa terhubung dengan produk tersebut.

Kansei Engineering memungkinkan kuantifikasi tanggapan multidimensi kansei pengguna dan menghubungkannya dengan atribut fugsionalitas perangkat lunak. Terbukti dari literatur yang ada bahwa deskripsi metode dalam Kansei Engineering adalah sebagian besar rinciannya berbentuk narasi, dan rincian detail Kansei Engineering yang paling lengkap tersedia dalam bahasa Jepang

Ishihara, 2005. Beberapa upaya telah dilakukan oleh para peneliti akademis untuk menjelaskan metode dalam sastra Inggris. Untuk memperbanyak literatur dari metodologi Kansei Engineering, prinsip dalam melaksanakan Kansei Engineering seperti pada gambar 1. Dalam gambar tersebut menguraikan prinsip Implementasi Kansei
Engineering yang mungkin dalam semua siklus pengembangan untuk berbagai jenis produk

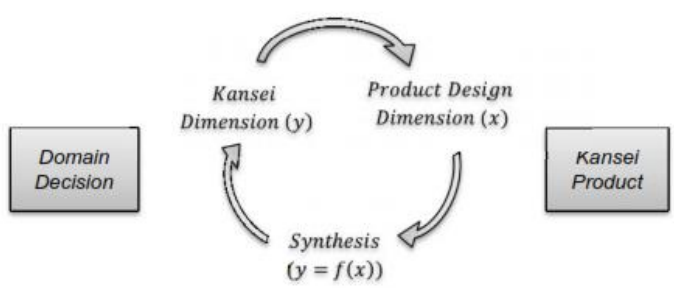

Gambar 1. Prinsip Implementasi Kansei Engineering[5]

Prosedur ini mencakup beberapa fase yaitu domain decision, kansei dimension, product design dimension dan synthesis, dalam tujuan pengembangan konsei produk.

1. Domain decision (penentuan domain) adalah fase untuk mengidentifikasi domain tertentu yang akan diselidiki menggunakan metodologi Kansei Engineering.

2. Kansei Dimension (Dimensi Kansei), poin ini terdiri dari tiga tahap :

a. Identifikasi Kansei

Pertama-tama, ekspresi dimensi kansei dalam bentuk kata sifat atau kata benda, disebut Kansei Words (KW), harus disiapkan. Biasanya jumlah awalnya disiapkan KW akan sangat besar, dan pengurangan angka ini dapat dilakukan dengan metode kualitatif dan kuantitatif.

b. Pengukuran Kansei

Pengukuran kansei adalah proses menangkap kansei konsumen.

c. Analis Kansei

Analisis kansei memberikan kesempatan bagi satu studi untuk menyelidiki makna yang sama, struktur dan konsep dalam kansei konsumen.

3. Kansei Product (Produk kansei) adalah produk yang dihasilkan dari pendekatan kualitatif dan kuantitatif dalam pelaksanaan Kansei Engineering.

Ada 8 jenis metodologi yang bisa digunakan dalam pengimplementasian

Kansei Engineering[5] yaitu :

1. Kansei Engineering Type I: Category Classification

2. Kansei Engineering Type II: Kansei Engineering Sistem 
3. Kansei Engineering Type III: Kansei Engineering Modeling

4. Kansei Engineering Type IV: Hybrid Kansei Engineering

5. Kansei Engineering Type V: Virtual Kansei Engineering

6. Kansei Engineering Type VI: Collaborative Kansei Engineering

7. Kansei Engineering Type VII: Concurrent Kansei Engineering

8. Kansei Engineering Type VIII: Rough Sets Kansei Engineering

\section{METODA PENELITIAN}

\subsection{Domain Decision (Penentuan Domain)}

Dalam studi Kansei Engineering, fokus ke domain tertentu sangat penting karena implementasi penelitian kansei unik terhadap produk yang berbeda. Penentuan domain dapat dilakukan dengan menggunakan teknik analisis pasar atau segmentasi target konsumen. Juga, keputusan harus dibuat apakah akan melakukan Kansei Engineering berdasarkan produk yang sudah ada atau untuk mulai merancang sebuah konsep produk baru dari awal. Pendekatan yang berbeda dapat digunakan, dan tidak dapat dikategorikan sebagai lebih baik dibandingkan dengan yang lain. Sebagai aturan praktis, domain dapat ditentukan berdasarkan adanya fleksibilitas untuk memperbaiki situasi yang ada[6].

\subsection{Kansei Dimension (Dimensi Kansei) 3.2.1. Identifikasi Kansei}

Pertama-tama, ekspresi dimensi kansei dalam bentuk kata sifat atau kata benda, disebut Kansei Words (KW), harus disiapkan. Biasanya jumlah awalnya disiapkan KW akan sangat besar, dan pengurangan angka ini dapat dilakukan dengan metode kualitatif dan kuantitatif.

\subsubsection{Pengukuran Kansei}

Pengukuran kansei adalah proses menangkap kansei konsumen. Karena kansei bersifat subyektif, ambigu dan terstruktur, tidak mungkin untuk mengukur secara langsung. Oleh karena itu, kita perlu merancang metode pengukuran tidak langsung dengan menggunakan pendekatan ekspresi alternatif[3]. Pengukuran kansei diklasifikasikan tindakan fisiologis dan tindakan psikologis.
Target Ukuran fisiologis untuk menangkap prilaku konsumen, Respon dan ekspresi tubuh. Hal ini dapat dilakukan dengan cara analisis gelombang otak dengan Electroencephalogram (EEG), pengukuran beban otot dengan electromyography (EMG), gerakan mata dan indikator ergonomis fisiologis lainnya yang digunakan untuk mengukur kansei ketika konsumen menggunakan atau melihat produk.

Ukuan psikologis berkaitan dengan kondisi mental manusia seperti perilaku konsumen, ekspresi, aksi, dan kesan. Hal ini dapat diukur dengan menggunakan sistem pelaporan diri seperti Different Emotional Scale (DES), Semantic Differential (SD) Scale atau sistem pelabelan bebas. Jenis-jenis pengukuran ini sangat populer dalam pelaksanaan Kansei Engineering karena kesederhanaannya.

\subsubsection{Analis Kansei}

Analisis kansei memberikan kesempatan bagi satu studi untuk menyelidiki makna yang sama, struktur dan konsep dalam kansei konsumen. Berikut ini menunjukkan beberapa analisis umum dilakukan untuk menganalisis kansei konsumen:

\section{A. Investigasi Persamaan Antara Variabel}

Tanggapan kansei berbeda dalam domain yang berbeda, sehingga identifikasi kesamaan memungkinkan penemuan kansei yang lebih obyektif yang mencerminkan domain. Dalam Kansei Engineering, Correlation Coefficient Analysis (CCA) banyak digunakan sebagai ukuran kekuatan hubungan antara variabel. Hal ini biasanya digunakan untuk mengukur korelasi antara kansei dalam suatu domain yang memungkinkan penyelidikan kesamaan antara kansei, sehingga kansei yang berkorelasi bisa diringkas. Namun hal ini bisa diabaikan jika memang Kansei Engineer ingin menggunakan semua variabel.

\section{B. Mendapatkan Komponen Utama (Principal Component)}

Meskipun studi ini dilakukan dengan menggunakan kansei yang lebih obyektif, diyakini bahwa masih akan menghasilkan beberapa redundansi variabel karena persepsi subyektif. Disini, redundansi berarti bahwa beberapa variabel berkolerasi dengan satu sama lain, mungkin karena mengukur 
kontruksi yang sama. Karena redundansi ini, diyakini bahwa itu memungkinkan untuk mengurangi variabel yang diamati dalam sejumlah kecil komponen utama yang akan menjelaskan sebagian besar dan varians dalam variabel yang diamati. Principal Component Analysis (PCA) adalah teknik reduksi data yang digunakan untuk mengidentifikasi satu set kecil variabel yang menjelaskan sebagian besar dari total varians dalam variabel asli. Komponen dapat dihitung dengan matriks korelasi (default) atau matrik kovarians. Output terdiri dari eigenvalues (yaitu, varians dari Principal Component), variability dan variability kumulatif dari total perbedaan dijelaskan oleh masing-masing Principal Component dan koefisien untuk masingmasing Principal Component.

Dalam Kansei Engineering, PCA umumnya digunakan untuk menemukan ruang semantik kansei dan spesimen, dan strategi kansei dapat ditentukan oleh PC vektor. Strategi kansei adalah penting karena dapat digunakan oleh perusahaan untuk menyusun strategi konsep baru suatu produk, dengan petunjuk pada desain produk pesaing. PCA dapat digunakan untuk memvisualisaikan beberapa banyak evaluasi pada kansei mempengaruhi variabel, dan $P C$ Score (scree plot) menampilikan kansei yang memiliki hubungan yang kuat dengan spesimen tertentu.

\section{Menentukan Konsep Kansei}

Factor Analysis (FA) adalah teknik reduksi data statistik yang digunakan untuk menjelaskan variabilitas antara variable acak yang diamati dalam hal variable acak yang tidak teramati lebih sedikit disebut faktor. FA mengasumsikan bahwa semua rating data pada atribut yang berbeda dapat dikurangi ke beberapa dimensi penting.

Penurunan ini dimungkinkan karena rating yang diberikan kepada salah satu atribut sebagian hasil dari pengaruh atribut lainnya. FA umumnya digunakan untuk menemukan struktur psikologis kansei yang merupakan konsep penting dari kansei dari domain yang diteliti. Hasilnya dapat digunakan untuk menyusun strategi konsep baru produk kansei yang mewakili kansei konsumen penentu dalam domain.

\subsection{Kansei Product (Produk Kansei)}

Sebuah produk kansei yang sukses dapat dikembangkan oleh penggabungan persyaratan desain yang dihasilkan oleh implementasi Kansei Engineering dan pengalaman keterampilan desainer produk. Ada banyak produk hasil dari Kansei Engineering seperti mobil, peralatan rumah tangga, dapur desain kabinet, desain komunitas virtual, desain interior pesawat, dan the list keep mounting.

Dalam pelaksanaannya, Kansei Engineering telah digunakan pada poin yang berbeda dari siklus pengembangan produk dimana fleksibilitas masuk akal untuk dilibatkan dalam membuat keputusan mengenai setiap aspek fungsionalitas sistem informasi.

\section{PENEMPATAN KANSEI ENGINEERING DALAM SIKLUS PENGEMBANGAN PERANGKAT LUNAK}

Sistem informasi merupakan salah satu produk dari pengembangan perangkat lunak, maka proses pengembangan fungsionalitas sistem informasi dengan pendekatan kansei engineering akan menjadi bagian dari siklus pengembangan perangkat lunak.

Kansei Engineering dipandang sebagai metode potensial untuk mengembangkan sistem informasi yang memiliki fungsionalitas sesuai dengan keinginan sekelompok pengguna. Gambar 2 menunjukkan konsep Kansei Engineering dalam pengembangan fungsionalitas sistem informasi.

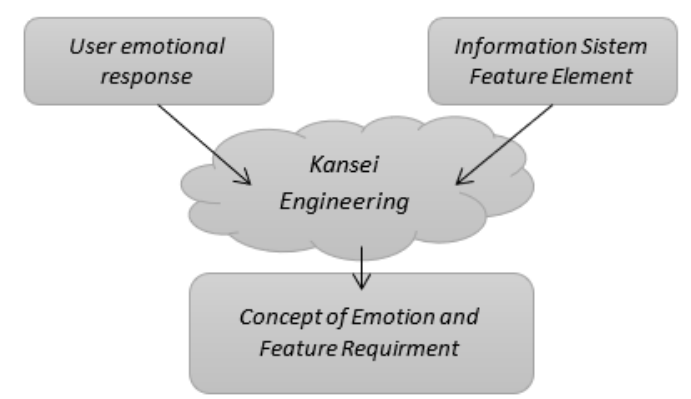

Gambar 2. Kansei Engineering dalam Pengembangan Fungsionalitas Sistem Informasi diadaptasi[6]

Secara umum proses rekayasa perangkat lunak terdiri dari lima tahapan[7], diantaranya :

1. Communication

2. Planning 


\section{Modeling \\ 4. Construction \\ 5. Deployment}

Karena hasil dari kansei engineering adalah konsep emosi dan kebutuhan persyaratan fungsionalitas sistem maka penempatannya dalam siklus pengembangan perengkat lunak terletak pada tahapan planning (perencanaan), seperti dintunjukan pada gambar 3 berikut.

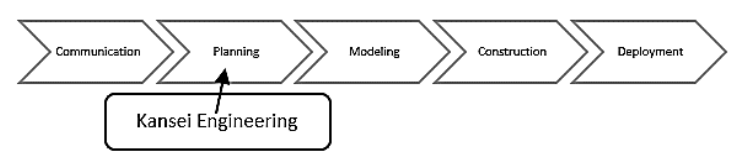

Gambar 3. Penempatan Kansei Engineering dalam Siklus Pengembangan Perangkat Lunak

\section{KESIMPULAN}

Proses pengembangan perangkat lunak termasuk didalamnya sistem informasi yang digunakan oleh sekelompok pengguna tertentu diharapkan akan lebih efektif dari segi fungsionalitasnya dan tentunya akan lebih efisien dalam pembiayaan, jika fungsi-fungsi yang dikembangkan sesuai dengan kebutuhan pengguna tersebut sehingga meminimalisir berbagai fungsi yang dibuat namun tidak dibutuhkan atau bahkan tidak sesuai dengan kebutuhan. Kansei engineering yang pada mulanya digunakan untuk menghasilkan pedoman desain produk termasuk pedoman desain antarmuka perangkat lunak sudah berkembang untuk digunakan dalam menginvestigasi kebutuhan fungsionalitas perangkat lunak. Adapun penempatan kansei enginnering dalam siklus pengembangan perengkat lunak adalah pada tahapan planning (perencanaan).

\section{DAFTAR PUSTAKA}

[1] Muhaemin, M. N. A. (2016). Implementasi Kansei Engineering dalam Desain Website Profile Perguruan Tinggi (Studi Kasus: STMIK Sumedang). Infoman's: Jurnal Ilmuilmu Manajemen dan Informatika, 10(2), 3948.

[2] Schütte, S. (2005). Engineering Emotional Values in Product Design. Linkopings Universitet, Department of Mechanical Engineering, Sweden.

[3] Ishihara, I., Nishino, T., Matsubara, Y., Tsuchiya, T., Kanda, F., Inoue, K. (2005). Kansei And Product Development (In Japanese), Ed. M. Nagamachi. Vol. 1. Kaibundo, Tokyo.

[4] Lokman, A. M., Khairul K. 1. Ana Hadiana. (2013). Premo and Kansei: A Comparative Analysis. Insan Akademika Publications, Indonesia.

[5] Lokman, A. M. (2010). Design \& Emotion: The Kansei Engineering Methodology. Universiti Teknologi Mara (Uitm), Malaysia

[6] Lokman, A. M. (2009). Emotional User Experience In Web Design: The Kansei Engineering Approach. Universiti Teknologi Mara (Uitm), Malaysia.

[7] Pressman, R. (2010). Software Engineering A Practicioner's Approach Seventh Edition, Prentice Hall. 